\title{
Epidemiology of Adenovirus and Genotypic Characteristics of Group A Rotavirus Among Diarrhoeic Children Aged 0 to 5 Years Old in the Ngaoundere Region of Cameroon
}

\author{
Kagning Tsinda Emmanuel ${ }^{1, ~ *, ~ F o k u n a n g ~ C h a r l e s ~ N t u n g w e n ², ~}$ \\ Tchuenguem Fohouo Fernand-Nestor ${ }^{3}$, Nwabo Kamdje Armel Herve ${ }^{1}$, Nukenine Elias Nchinwan ${ }^{3}$ \\ ${ }^{1}$ Department of Biomedical Sciences, University of Ngaoundere, Ngaoundere, Cameroon \\ ${ }^{2}$ Department of Pharmacotoxicology and pharmacokinetics, University of Yaounde I, Yaounde, Cameroon \\ ${ }^{3}$ Department of Biological Sciences, University of Ngaoundere, Ngaoundere, Cameroon
}

\section{Email address:}

kagningemmanuel@gmail.com (K. T. Emmanuel)

\section{To cite this article:}

Kagning Tsinda Emmanuel, Fokunang Charles Ntungwen, Tchuenguem Fohouo Fernand-Nestor, Nwabo Kamdje Armel Herve, Nukenine Elias Nchinwan. Epidemiology of Adenovirus and Genotypic Characteristics of Group A Rotavirus Among Diarrhoeic Children Aged 0 to 5 Years Old in the Ngaoundere Region of Cameroon. Science Journal of Public Health. Vol. 3, No. 4, 2015, pp. $525-537$.

doi: $10.11648 /$ j.sjph.20150304.21

\begin{abstract}
In the context of recent introduction of a Rotavirus vaccine, little is known about the epidemiology of Rotavirus and Adenovirus gastroenteritis in Cameroon in general and in Ngaoundere specifically. The main objective of this study was to determine the frequency of Rotavirus and Adenovirus antigens as well as to characterise circulating Rotavirus strains in children with diarrhoea in Ngaoundere. A convenience sampling method was used and stool samples collected from patients consulting at the study sites from April to July 2014 were subjected to a qualitative immunochromatographic test to detect group antigens of group A Rotavirus and Adenovirus. Socio-demographic data were collected using a pre-tested questionnaire. Stool samples tested positive for Group A Rotavirus were genotyped by multiplex nested RT-PCR method. Logistic regression, Chi-square or Fisher's exact tests were performed when appropriate. P-value $<0.05$ at $95 \%$ confidence interval was considered statistically significant. Adenovirus antigen was detected in 26.4\% (56) of children, whereas, group A Rotavirus was detected in $2.3 \%$ (5); the co-infection rate was $5.3 \%$. Vomiting, fever, moderate dehydration, severe dehydration and the presence of polymorphonuclear cells in stool were significantly associated with the presence of Adenovirus antigen in stool. Group A Rotavirus was also found to circulate in Ngaoundere and the G1P[8] genotype showed indication of being the most represented. Adenovirus antigen was shown to be an important agent in childhood acute gastroenteritis in Ngaoundere and this study has been used as a baseline data for this infection in this region of Cameroon. The appropriate management of viral acute gastroenteritis necessitates the detection of Rotavirus and Adenovirus in clinical routine practice. Furthermore, Rotarix ${ }^{\mathrm{TM}}$ vaccination should be encouraged and the populations should be educated on hygiene practices.
\end{abstract}

Keywords: Rotavirus, Adenovirus, Epidemiology, Genotypes, Children Aged 0 to 5 Years

\section{Introduction}

The United Nations Millennium Development Goal number four was to reduce the mortality rate of children under 5 years of age by $2 / 3$ by 2015 from 1990 figures [1]. To achieve this goal after 2015, the world must tackle diarrheal diseases, which are the second largest cause of death of children under 5 years and are responsible for 1.5 million deaths worldwide every year [2]. In effect, enteric viruses have been recognized as the most significant etiological agents of acute gastroenteritis and Group A Rotavirus, Norovirus, group F Adenovirus and Astrovirus are considered as clinically relevant [3]. Besides, the ability of Adenoviruses to cause acute infection in both the gastrointestinal tract and the respiratory system makes them quite dangerous, especially in children aged less than 5 years. It has been reported that they cause about $5 \%$ of all infectious diseases in infants and nearly $3 \%$ in children aged 2 to 4 years old [4]. Other studies revealed that group $\mathrm{F}$ (types 40 and 41) and group A (type 31) Adenovirus are the sole Adenoviruses that have been found associated with 
gastroenteritis in infants and young children [5-6].

In Cameroon, available data suggest that the Rotavirus kills $196 \%$ of the under 5 years old [7]. Additionally to these alarming statistics of RVA, enteric Adenoviruses further increase those figures, even though, data is lacking to measure its real burden in the population: Adamawa region which is the third most affected region by infantile diarrhoea in Cameroon paradoxically has no available data related to the epidemiology of gastroenteritis due to Group A Rotavirus and enteric Adenovirus (to the best of our knowledge) [8]. Furthermore, the Rotarix ${ }^{\mathrm{TM}}$ vaccination was introduced (in March 2014), by ministry of public health while the Adamawa region was in a context of missing epidemiological data related to RVA infections. Ruiz-Palacios and collaborators reported in 2006 that one of the major challenge for Rotarix ${ }^{\mathrm{TM}}$ is the protection against G2P[4] and G9P[6], even though there is a data void in the RVA circulating strains in Ngaoundere [9]. So, the research question of this study is the following: What are the epidemiological characteristics of circulating Rotavirus and Adenovirus causing gastroenteritis in children aged 0 to 5 years in Ngaoundere? Thus, this study was conducted to assess and provide a baseline data on the epidemiology of RVA and Adenovirus in the Adamawa region and to upgrade the limited information on RVA and Adenovirus diarrhoea in the country. This study was also necessary to develop an insight into the genotypes of circulating RVA in the region as well as the prevalence of Adenovirus antigens in diarrhoeic children aged less than 5 years the Adamawa region. The leading hypothesis of this study is that the prevalence of RVA and Adenovirus antigens in stool are both high, with socio-demographical and geographical factors being the determinants of these viral infections in our study site. We also hypothesise that due to the reassortment capacity of the Rotavirus, the distribution of RVA strains in Ngaoundere is different from those frequently observed elsewhere in the world.

The general objective of this study was to investigate the burden of RVA (as well as its genotypes) and Adenovirus antigens considering some outcomes associated with their presence in stool specimen of children aged 0 to 5 years in the Ngaoundere city. Among children aged 0 to 60 months presenting with acute diarrhoea, this study specifically strived to:

- determine the prevalence rates of RVA and Adenovirus antigens according to age, gender; educational level of parents, clinical condition, zone of residence, the child's feeding pattern, the origin of water consumed at home, macroscopy of the stool specimen;

- determine the variables which are associated with either the infection (RVA/Adenovirus) or with co-infection in children aged $0-5$ years.

\section{Materials and Methods}

\subsection{Study Design, Sampling and Population}

We carried out a cross sectional and analytical study in the Ngaoundere. Through convenience sampling, we recruited
263 children aged 0 to 5 years presenting acute diarrhoea in our four study sites: the Regional Hospital Ngaoundere; the Protestant Hospital of Ngaoundere, the Integrated Health Centre of Sabongari, and the Integrated Health Centre of Dang.

Ngaoundere is a city of the Vina division in the Adamawa region, located at $719^{\prime}$ North / 13 35' East / 7.32, 13.58 [10]. The altitude of the said city is $1104 \mathrm{~m}$ and in 2005, its estimated population was 262747 persons, with a density of 13.9 inhabitants $/ \mathrm{km}^{2}$ [11-12]. The major occupation of populations in the study area is subsistence agriculture supplemented with fishing and dairy farming [10]. Ngaoundere has a tropical humid climate and its vegetation is made up of savannah. The region is under the influence of both a dry season (November-March) and a rainy season (April-October). The total annual precipitation averages $1496.7 \mathrm{~mm}$ and the temperature is close to $22{ }^{\circ} \mathrm{C}$ [12]. The city is administratively divided into three sub-divisions: Ngaoundere 1, Ngaoundere 2 and Ngaoundere 3. The residence areas of our study population were subdivided on the basis of the following quarters:

- Ngaoundere 1: Bali 1, Bali 2, Norvégien, Burkina, Mboumdjéré, Mbiden, Marza, Hauts plateaux ;

- Ngaoundere 2: Baladji 1 et 2, Tongo, Sabongari 1, 2, 3 ; Madagascar, Champ de prière, Onaref, Somino, Aéroport, Gadamabanga, Gambara, Jolisoir, Aoudi;

- Ngaoundere 3: Mboum; Bidjoro, Malang, Malo-Goni, Manwi, Bini, Dang.

\subsection{Inclusion Criteria}

All in or outpatients aged 0 to 5 years old, whose primary complaint (explained by the parents/guardian) was acute gastroenteritis and whose parents gave their assent for participation in the study.

\subsection{Exclusion Criteria}

We excluded from our study:

- stool samples pre-collected by parents in a nonconventional manner. (e.g. Samples collected in tree leaves or any plastic wrapping tissue before bringing it to the hospital);

- patients suffering from any hospital acquired gastroenteritis occurring 48 hours after hospitalization;

- low volume samples (less than $0.5 \mathrm{ml}$ );

- patients with diarrhoea which lasted more than 15 days.

\subsection{Sample Collection}

Different stool samples were collected based on the WHO generic protocol for hospital based surveillance of Rotavirus to estimate the burden of Rotavirus gastroenteritis in children less than five years of age [13]. The samples were then transported to the laboratory as early as possible.

Acute gastroenteritis was diagnosed by the paediatrician who consulted the children on their arrival at consultation room. After informed consent was obtained, we filled out the socio-demographic data and information on clinical 
symptoms on a standardized questionnaire, and then proceeded with stool sample collection. The procedure of sample collection was as follows:

- after wearing a pair of gloves, the stool specimen was collected in a clean, dry container; care was taken not to contaminate the specimen with urine;

- an open mouth sterile and dry stool container was used. At least a marble-size specimen was transferred to the container. If the specimen was "runny", it was simply poured into the container. The container was labelled with patient's code, study site and date of collection;

- the specimen was transferred to the laboratory (alongside the completed and duly signed questionnaire) and frozen at 20 degrees Celsius. All the samples were later transported (in a cold chain) to the Regional hospital's laboratory where $10 \%$ suspension (by adding $100 \mu \mathrm{l}$ of stool in $900 \mu \mathrm{l}$ of nuclease free water and mixing using a vortex) of samples that were positive for group A Rotavirus were prepared and stored until analysis.

\subsection{Detection of Group A Rotavirus and Adenovirus Antigen}

\subsubsection{Qualitative Detection}

Detection of Group A Rotavirus and Group F Adenovirus was done using Rota-Adeno stick from Biocare Diagnostics Ltd. This rapid chromatographic (lateral flow) immunoassay kit simultaneously detects group A Rotaviruses and Adenoviruses in stool specimens [14].

The test uses new homogenous immunochromatographic system with gold particles. It is a ready test to be used, which only needs a faecal sample dilution with the supplied ready to use dilution buffer. Specificity was ensured using monoclonal antibodies conjugated with gold particles and directed against specific human genus-specific Rotavirus antigens or
Adenovirus antigens. The immunochromatographic stick was coated with a polyclonal antibodies specific for genus specific Rotavirus VP6 antigen and Adenovirus hexon antigens. Liquid sample and gold conjugate both migrate by capillarity and reach the first specific anti-Adenovirus polyclonal antibodies. If Adenovirus is present in the sample, it is blocked and immunoreaction appears as a red-pink line. As the sample still migrates, it reaches the second specific reagent line against Rotavirus, then migrates to the nonspecific anti-mouse Ig $\mathrm{G}$ which gives rise to a third red pink line. This rear line indicates that the chromatography has been developed without hindrance. It appears also with samples which are does not contain the virus [14].

The performance of the test as compared to Enzyme Linked Immunosorbent Assay (ELISA) is the following: RVA specificity: 98\%; RVA sensitivity: $96 \%$; Adenovirus specificity: 98.3\%; Adenovirus sensitivity: 95\% [14].

Before starting the qualitative test procedure [14], all reagents and samples were allowed to come to room temperature:

- $0.5 \mathrm{ml}$ of extraction buffer was dispensed in a testing tube;

- using a sterile wooden applicator, a sample portion of approximately 5-6 $\mathrm{mm}$ size $(25-50 \mathrm{mg})$ was collected. The applicator was pressed to the tube while rotating it at the same time. For liquid or semi-solid stools, we added 100 microliters of stool using an appropriate pipette;

- the sample was stirred to homogenize and release the virus into the diluent;

- a strip was dipped it into the testing tube with the arrow pointing to the bottom;

- the test strip was incubated at room temperature for 15 minutes, and then was read.

Table 1. Primers used for VP4 PCR genotyping [17].

\begin{tabular}{llll}
\hline Primer (Polarity) & Sequence $\left(\mathbf{5}^{\prime} \rightarrow \mathbf{3}^{\prime}\right)$ & Position & Gene / Type \\
\hline VP4 consensus oligonucleotide primers & & & \\
con3 $(+)$ & TGG CTT CGC TCA TTT ATA GAC A & nt 11-32 & VP4 \\
con2 (-) & ATT TCG GAC CAT TTA TAA CC & nt 868-887 & \\
P type-specific oligonucleotide primers & & & P[4] \\
2T-1(-) & CTA TTG TTA GAG GTT AGA GTC & nt 474-494 & P[6] \\
3T-1(-) & TGT TGA TTA GTT GGA TTC AA & nt 259-278 & P[8] \\
1T-1(-) & TCT ACT TGG ATA ACG TGC & nt 339 -356 & P[9] \\
4T-1(-) & TGA GAC ATG CAA TTG GAC & nt 385-402 & P[10] \\
5T-1(-) & ATC ATA GTT AGT AGT CGG & nt 575-594 & P[8] \\
1T-1 Wa $(-)$ & TCT ACT GGG TTA ACG TGC & Nt 339-356 & P[8] \\
1T-1 VN (-) & TCT ACT GGA TCG ACG TGC & Nt 339-356 & \\
\hline
\end{tabular}

$(+)$ forward

$(-)$ reverse

\subsubsection{Rotavirus RT-PCR Genotyping}

The viral dsRNA was extracted from the $10 \%$ stool suspension using the QIAamp Viral RNA mini kit, according to the manufacturer's instruction (QIAGEN Kit). The extracted dsRNA of each strain was denatured and then reverse transcription-PCR (RT-PCR) was carried out using a One-Step RT-PCR kit (Qiagen, Valencia, CA) according to 
manufacturer's instructions. In brief, denaturation of dsRNA was carried out at $94^{\circ} \mathrm{C}$ for 3 minutes, then reverse transcription carried out at $42^{\circ} \mathrm{C}$ for 30 minutes, activation of Taq polymerase at $95^{\circ} \mathrm{C}$ for 15 minutes followed by 30 cycles of PCR (denaturing at $94^{\circ} \mathrm{C}$ for $30 \mathrm{sec}$, annealing at $42^{\circ} \mathrm{C}$ for $30 \mathrm{sec}$, and extension at $72^{\circ} \mathrm{C}$ for $45 \mathrm{~min}$ ) and a final extension $\left(72^{\circ} \mathrm{C}\right.$ for $\left.7 \mathrm{~min}\right)$. Genotyping of the VP7 and VP4 genes was done by multiplex semi-nested PCR assay. For both $\mathrm{G}$ and P-type determination, a series of type-specific primers were used (including G1-G4, G8, G9, G12 primers and $\mathrm{P}[4], \mathrm{P}[6], \mathrm{P}[8], \mathrm{P}[9]$ and $\mathrm{P}[10]$ primers [15-16]. The amplified RNA segments were then ran on $3 \%$ Agarose gel (Seakem $^{\mathrm{TM}}$ LE agarose-Fisher Scientific) electrophoresis in standard Tris-Acetate-EDTA buffer to determine samples positive for each RVA strain. Gels were stained with Gel red $\left(\right.$ Biotum $\left.^{\mathrm{TM}}\right)$. A sample was positive for P9, P10, P8, P6, P4, G1-G4, G8, G9 and G12 if the PCR sample co-migrates with the molecular weight markers of each genotype.

Table 2. Primers used for VP7 PCR genotyping [17].

\begin{tabular}{|c|c|c|c|}
\hline Primer & Sequence $\left(5^{\prime} \rightarrow 3^{\prime}\right)$ & Position & Gene / Type \\
\hline \multicolumn{4}{|c|}{ VP7 consensus oligonucleotide primers } \\
\hline $9 \operatorname{con} 1-\mathrm{L}(+)$ & TAG CTC CTT TTA ATG TAT GGT AT & nt $37-59$ & \multirow{2}{*}{ VP7 } \\
\hline VP7-Rdeg(-) & AAC TTG CCA CCA TYT YTT CC & nt 914-933 & \\
\hline \multicolumn{4}{|c|}{ VP7 type specific oligonucleotide primers } \\
\hline 9T-1(-) & TCT TGT CAA AGC AAA TAA TG & nt $176-195$ & G1 \\
\hline 9T-2(-) & GTT AGA AAT GAT TCT CCA CT & nt $262-281$ & G2 \\
\hline 9T-3(-) & GTC CAG TTG CAG TGT AGC & nt $484-501$ & G3 \\
\hline 9T-4(-) & GGG TCG ATG GAAAAT TCT & nt $423-440$ & G4 \\
\hline aAT8(-) & GTC ACA CCA TTT GTA AAT TCG & nt $178-198$ & G8 \\
\hline 9T-9(-) & TAT AAA GTC CAT TGC AC & nt $131-147$ & G9 \\
\hline G12(-) & CCG ATG GAC GTA ACG TTG TA & nt 548-567 & G12 \\
\hline
\end{tabular}

\subsection{Ethical Consideration}

An ethical clearance $\left(\mathrm{N}^{\mathrm{o}} 2014 / 06 / 465 / \mathrm{L} / \mathrm{CNERSH} / \mathrm{SP}\right)$ was obtained on the $11^{\text {th }}$ June 2014 from the Cameroon National Ethics Committee for Research on Humans. Additionally, an informed consent was obtained prior to stool and data collection.

\subsection{Statistical Analyses}

Data was coded and entered into a computer database. Rates and proportions were calculated and the results presented using frequency tables. Statistical data analyses were performed using the 2.13 version of $\mathrm{R}$ software. Categorical data were presented in two-way contingency table analyses using Pearson's Chi-square tests of independence or the Fisher's exact test (when expected frequencies were less than 5). Logistic regression was also used to isolate the effects of predictor variables and confounders. Adjusted odds ratios with $95 \%$ confidence intervals were calculated whilst performing the logistic regression. $P<0.05$ was considered significant. ANOVA or its non-parametric equivalent was used where appropriate.

\subsection{Operational Definitions}

Epidemiology is the study of the distribution and determinants of health-related states or events in specified populations and the application of this study to control of health problems [18]. Therefore, epidemiology describes health and disease in terms of frequencies and distributions of determinants and conditions in a population or in a specific group of a population. Epidemiology also includes the study of associations between specific diseases and factors to which populations are exposed [19]. An acute diarrhoeic case in this study was defined as a child passing off more than 3 looser than normal stools (liquid, watery or a bloody stool) three or more times in a 24-hour period as reported by parents [20], occurring over a less than 14 days. The storage temperature of the freezer was daily checked using an in-built or an external thermometer. The dehydration management criteria that we considered were as follows:

Plan A: mild dehydration, treatment prescribed by the nurse $=$ food and water consumption at home.

Plan B: at least two of the following signs: sunken eyes, irritability, polydipsia, skin turgor, insomnia. The treatment prescribed by the nurse/medical doctor is usually the ORS. Plan C: skin turgor; sunken eyes / fontanels, lethargy, Treatment prescribed by the nurse/medical doctor $=\mathrm{IV}$ rehydration [21].

The level of dehydration was assessed using the Vesikari 20 -point scoring scale, which is the most commonly used scoring scale to assess gastroenteritis disease severity [22]. While using this scoring scale, episodes of gastroenteritis with scores $\geq 11$, between $7-10$ and $<7$ are respectively considered as severe, moderate and mild [22]. Grading the severity score takes into account: maximum number stools per day, diarrhoea duration (days), maximum number of vomiting episodes per day, vomiting duration (days), temperature, treatment (rehydration/hospitalisation). We considered that a child has received Rotarix ${ }^{\mathrm{TM}}$ if that was written on his vaccination card. Finally, we considered polymorphonuclear cells as white blood cells visualized 
under the microscope $40 \mathrm{X}$ objective on a wet mount.

\section{Results}

\subsection{Adenovirus Antigen}

\subsubsection{Adenovirus Prevalence}

56 children were positive for Adenovirus antigen in stool, thus giving a prevalence rate of $26.42 \%$

\subsubsection{Frequency of Adenovirus Antigen in Stool with Respect to Socio-Demographics Parameters}

(i) Positivity Rate of Adenovirus According to Gender

The frequency of Adenovirus was found to be almost similar between females $(26.4 \%)$ and males $(27 \%)$ children as shown by Table 3 .

Table 3. Frequency of Adenovirus antigen according to gender.

\begin{tabular}{llll}
\hline Gender & $\begin{array}{l}\text { Adenovirus Negative } \\
\text { Number }(\%)\end{array}$ & $\begin{array}{l}\text { Adenovirus positive } \\
\text { Number }(\%)\end{array}$ & P value \\
\hline Male & $82(73)$ & $31(27)$ & 0.8 \\
Female & $67(72.6)$ & $24(26.4)$ & $\begin{array}{l}\chi^{2}=0.02, \\
\mathrm{df}=1\end{array}$ \\
\hline
\end{tabular}

(ii) Positivity rate of Adenovirus according to age

There was no statistical significant association between the age and the Adenovirus presence in stool (Table 4).

Table 4. Distribution of the Adenovirus positivity rate according to age.

\begin{tabular}{llll}
\hline $\begin{array}{l}\text { Age groups } \\
\text { (months) }\end{array}$ & $\begin{array}{l}\text { Number of positive } \\
\text { cases ( \% ) }\end{array}$ & Total & p-value \\
\hline $0-12$ & $26(28.6)$ & 91 & \\
$13-24$ & $17(23)$ & 74 & \\
$25-36$ & $4(25)$ & 16 & $0.9^{\mathrm{F}}$ \\
$37-48$ & $4(30.8)$ & 13 & \\
$49-60$ & $2(28.6)$ & 7 & \\
Total & $53(100)$ & 201 & \\
\hline
\end{tabular}

$\mathrm{F}=$ result obtained after performing the Fisher's exact test

\subsubsection{Frequency of Adenoviral Antigen in Stool with Respect to Clinical Data}

Table 5 summarises the frequency of Adenovirus with respect to clinical data and results of bivariate data analyses. All involved patients had diarrhoea, but not all were vomiting. We found a significant relationship between vomiting (variable 3) and Adenovirus positivity. In fact, around most children $(37.1 \%)$ with Adenovirus antigen in stool were vomiting. Furthermore, we noticed that children with Adenovirus in stool vomited more frequently than those who did not have (Table 6). Conversely, no relationship was found between Adenovirus positivity and vomiting duration.

We also compared the average number of stools passed out by children included in our study (Table 6). We found that the mean number of stool passed by Adenovirus infected patients was significantly higher than that of non-infected children. Additionally, a significant association between number of daily stool episodes and the positivity to adenoviral antigen was found (variable 1 in Table 5). We could not find any bivariate relationship between presence of adenoviral antigen and diarrhoea duration even though the data suggest that most Adenovirus positive (36\%) patients had diarrhoea which lasted more than 6 days.

We detected a statistically significant relationship between temperature (variable 7) and presence of Adenoviral antigen in stool $(P<0.0004)$. In effect, most patients tested positive had a temperature ranging from 39 to $39.9^{\circ} \mathrm{C}$. Additionally, there was a significant difference between the mean temperature of adenoviral positive and negative patients, with the temperature of positive patient being higher (Table 6).

Concerning the severity of the diarrhoea caused, we found that the presence of adenoviral antigen in stool was significantly related to the level of dehydration (variable 9). Similarly, most of the dehydration management put in place by health personnel were more often plan $\mathrm{C}(55.8 \%)$ and $\mathrm{B}$ $(21.7 \%)$ (variable 10$)$. In the same vein, adenoviral antigen was found to be more prevalent in external patients (53.8\%) than in admitted patients (46.2\%) (variable 11).

We did not find a significant association between the presence of adenoviral antigen in stool and co-existence of fever and vomiting (variable 8). Neither did we find a significant difference between adenoviral positive and negative children concerning: the mean ages, the mean weight and the hospital setting, abdominal pain, fatigue and irritability.

\subsubsection{Frequency of Adenovirus with Respect to Exposure to other Probable Risks Factors}

We assessed other risks factors of enteric infections among the 0 to 5 years old children in the Ngaoundere city. The results are presented in Table 7 . We found, after bivariate analyses that none of the variables (educational level, type of water consumed, mode of nutrition, parent or guardian's occupation, ethnic group and quarter) were significantly associated with the positivity to Adenovirus antigen.

\subsubsection{Frequency of Adenoviral Antigen in Stool with Respect to Stool Macroscopic and Microscopic Parameters}

The presence of Adenovirus antigen in stool was investigated with respect to some parameters which are usually considered when performing medical laboratory analyses on stool samples. Those parameters depicted in Table 8 are usually: the colour, consistency, the presence or absence of leucocytes and the presence or absence of yeast cells. The only variable associated to the presence of Adenoviral antigen in children was the presence of leucocytes in the stool. The colour, the consistency and presence of yeast cells were not significantly associated with Adenovirus positivity. 

Among Diarrhoeic Children Aged 0 to 5 Years Old in the Ngaoundere Region of Cameroon

Table 5. Clinical characteristics according to presence of Adenovirus antigen in stool.

\begin{tabular}{|c|c|c|c|c|}
\hline Variable & Categories & Adenovirus Positive: $\mathbf{n}(\%)$ & Adenovirus Negative: $\mathbf{n}(\%)$ & P-value \\
\hline \multirow{3}{*}{ 1.Number of diarrhoea episodes } & $1-3$ & $13(15.1)$ & $73(84.9)$ & \multirow{3}{*}{$0.02^{\mathrm{F}}$} \\
\hline & $4-5$ & $19(44.2)$ & $24(55.8)$ & \\
\hline & 6 & $14(42.4)$ & $19(57.6)$ & \\
\hline \multirow{3}{*}{ 2.Diarrhoea duration (days) } & $1-4$ & $27(21.8)$ & $97(78.2)$ & \multirow{3}{*}{$0.19^{\mathrm{F}}$} \\
\hline & 5 & $3(23.1)$ & $10(76.9)$ & \\
\hline & $\geq 6$ & $18(34.6)$ & $34(65.4)$ & \\
\hline \multirow{2}{*}{ 3. Vomiting } & Yes & $26(37.1)$ & 44 & \multirow{2}{*}{$\begin{array}{l}0.09^{\mathrm{C}} \\
\chi^{2}=6.1 \mathrm{ddl}=1\end{array}$} \\
\hline & No & $25(20.2)$ & 99 & \\
\hline \multirow{3}{*}{ 4. Number of vomiting episodes / day } & $<2$ & $40(25.2)$ & 119 & \multirow{3}{*}{$0.5^{\mathrm{F}}$} \\
\hline & $2-4$ & $6(27.3)$ & 16 & \\
\hline & $\geq 5$ & $4(40)$ & 6 & \\
\hline \multirow{3}{*}{ 5.Vomiting duration (days) } & $<2$ & $35(24.1)$ & 110 & \multirow{3}{*}{$0.32^{\mathrm{F}}$} \\
\hline & $2-4$ & $8(33.3)$ & 16 & \\
\hline & $\geq 5$ & $8(36.4)$ & 14 & \\
\hline \multirow{2}{*}{ 6. Fever $(\%)$} & Yes & $33(66.07)$ & $57(41.3)$ & \multirow{2}{*}{$<0.001^{\mathrm{c}}$} \\
\hline & No & $18(35.29)$ & $81(58.7)$ & \\
\hline \multirow{4}{*}{ 7. Temperature $\left({ }^{\circ} \mathrm{C}\right)$} & $<37.9$ & $14(18.2)$ & $63(81.8)$ & \multirow{4}{*}{$<0.0004^{\mathrm{F}}$} \\
\hline & $38-38.9$ & $15(24.2)$ & $47(75.8)$ & \\
\hline & $39-39.9$ & $13(65)$ & $7(35)$ & \\
\hline & $>40$ & $2(25)$ & $6(75)$ & \\
\hline \multirow{2}{*}{ 8. Fever+vomitting } & Yes & $19(43.1)$ & $25(56.9)$ & \multirow{2}{*}{$0.1609^{\mathrm{F}}$} \\
\hline & No & $21(29.5)$ & $50(70.5)$ & \\
\hline \multirow{3}{*}{ 9. Dehydration } & Mild & $7(8.5)$ & 75 (91.5) & \multirow{3}{*}{$<0.0001^{\mathrm{F}}$} \\
\hline & Moderate & $25(30.9)$ & $55(69.1)$ & \\
\hline & Severe & $19(57.6)$ & $14(42.4)$ & \\
\hline \multirow{3}{*}{ 10.Management of dehydration } & Plan A & $2(7.7)$ & $24(44.2)$ & \multirow{3}{*}{$<0.0001^{\mathrm{F}}$} \\
\hline & Plan B & $23(21.7)$ & $83(78.3)$ & \\
\hline & Plan C & $24(55.8)$ & $19(44.2)$ & \\
\hline \multirow{2}{*}{ 11.Admission status } & Outpatient & $28(20.4)$ & $109(79.6)$ & \multirow{2}{*}{$<0.0001^{\mathrm{F}}$} \\
\hline & Admitted & $24(51.1)$ & $23(48.9)$ & \\
\hline \multirow{4}{*}{ 12.Hospital setting } & RHN & $24(25.5)$ & $70(74.5)$ & \multirow{4}{*}{$0.27^{\mathrm{F}}$} \\
\hline & PHN & $6(35.3)$ & $11(64.7)$ & \\
\hline & $\mathrm{SAB}$ & $26(29.2)$ & $63(70.8)$ & \\
\hline & DA & $0(0)$ & $8(100)$ & \\
\hline \multirow{2}{*}{ 13.Abdominal pain } & Yes & $3(14.2)$ & $21(85.8)$ & \multirow{2}{*}{$0.13^{\mathrm{F}}$} \\
\hline & No & $53(28.6)$ & $132(71.4)$ & \\
\hline 14 Fatioue & Yes & $19(37.3)$ & $32(62.7)$ & $006843^{\mathrm{F}}$ \\
\hline & No & 37 (23.4) & $121(76.6)$ & \\
\hline 15 Irritability & Yes & $3(50)$ & $3(50)$ & 0.3 \\
\hline 15.ntiadity & No & $53(26.3)$ & $148(73.7)$ & \\
\hline
\end{tabular}

$\mathrm{F}=$ results obtained using the Fisher's exact test

$\mathrm{c}=$ result obtained through the chi-square test of independence

$\mathrm{n}=$ Number of cases

Table 6. Comparison of various means (temperature, vomiting, daily stools, age and weigh)t according to the positivity to Adenovirus.

\begin{tabular}{llll}
\hline Parameter (mean $\pm \boldsymbol{s} \boldsymbol{d})$ & $\begin{array}{l}\text { Adenovirus Negative } \\
\text { mean } \pm \boldsymbol{s} \boldsymbol{d}(\mathbf{n})\end{array}$ & $\begin{array}{l}\text { Adenovirus positive } \\
\text { mean } \pm \boldsymbol{s} \boldsymbol{d}(\mathbf{n})\end{array}$ & P-value \\
\hline Temperature $\left({ }^{\circ} \mathrm{C}\right)$ & $38.12 \pm 1.08(123)$ & $37.5 \pm 1(44)$ & $0.0023^{*}$ \\
Number of vomiting episodes & $1.52 \pm 1.6(141)$ & $0.86 \pm 1.9(50)$ & $0.005^{*}$ \\
Duration of vomiting (days) & $2.74 \pm 2.7(17)$ & $1.29 \pm 4.6(5)$ & $0.011^{*}$ \\
Duration of diarrhoea (days) & $6 \pm 6.2(16)$ & $4.95 \pm 5.1(8)$ & $0.04^{*}$ \\
Weight (Kg) & $9.66 \pm 3.7(104)$ & $9.97 \pm 3.4(45)$ & $0.665^{*}$ \\
Age (years) & $16.91 \pm 13(148)$ & $17.84 \pm 14.2(53)$ & $0.73^{*}$ \\
\hline
\end{tabular}

$*=$ results obtained using Kruskal Wallis test for group comparison of means

$\mathrm{n}=$ total number of observations 
Table 7. Positivity to Adenoviral antigen according to some risks factors.

\begin{tabular}{|c|c|c|c|c|}
\hline Variables & Categories & Adenovirus positive : n (\%) & Adenovirus negative : $\mathbf{n}(\%)$ & P-value \\
\hline \multirow{5}{*}{ Educational level } & None & $13(27.7)$ & $37(32.2)$ & \multirow{4}{*}{$0.70^{\mathrm{F}}$} \\
\hline & Primary & $21(44.7)$ & $42(36.5)$ & \\
\hline & Secondary & $8(17)$ & $26(22.6)$ & \\
\hline & University & $5(10.6)$ & $10(8.7)$ & \\
\hline & Wells/Forages & $20(36.3)$ & $37(25.7)$ & \multirow{4}{*}{$0.1^{\mathrm{F}}$} \\
\hline \multirow{3}{*}{$\begin{array}{l}\text { Type of water } \\
\text { consumed }\end{array}$} & Tap & $27(49.2)$ & $90(62.5)$ & \\
\hline & Stream & $2(3.6)$ & $9(6.25)$ & \\
\hline & Mineral & $6(10.9)$ & $8(5.5)$ & \\
\hline \multirow{3}{*}{ Mode of nutrition } & Breastfeeding & $21(36.2)$ & $59(36.8)$ & \multirow{3}{*}{$0.9^{\mathrm{F}}$} \\
\hline & Bottle-feeding & $5(8.62)$ & $16(10)$ & \\
\hline & Home-made meals & $32(55.18)$ & $85(53.12)$ & \\
\hline \multirow{12}{*}{$\begin{array}{l}\text { Parent/ guardian's } \\
\text { occupation }\end{array}$} & Bureaucrat & $1(2.27)$ & $10(8.3)$ & \multirow{12}{*}{$0.6^{\mathrm{F}}$} \\
\hline & Driver & $2(4.54)$ & $2(1.66)$ & \\
\hline & Trader & $3(6.81)$ & $18(15)$ & \\
\hline & Farmer & $7(15.9)$ & $13(10.83)$ & \\
\hline & Student & $2(4.54)$ & $2(1.66)$ & \\
\hline & Teacher/lecturer & $1(2.27)$ & $3(2.49)$ & \\
\hline & Breeder & 0 & $3(2.49)$ & \\
\hline & Garage man & $1(2.27)$ & $1(0.83)$ & \\
\hline & Housewife & $27(61.3)$ & $64(53.3)$ & \\
\hline & Military & 0 & $1(0.83)$ & \\
\hline & Tailor & 0 & $1(0.83)$ & \\
\hline & Other & 0 & $2(1.66)$ & \\
\hline \multirow{3}{*}{ Zone of residence } & Ngaoundere 1 & $10(27.02)$ & $32(27.6)$ & \multirow{3}{*}{$0.4^{\mathrm{F}}$} \\
\hline & Ngaoundere 2 & $20(50.05)$ & $71(61.2)$ & \\
\hline & Ngaoundere 3 & $7(18.9)$ & $13(11.2)$ & \\
\hline
\end{tabular}

*= results obtained using Kruskas Wallis test for group comparison of means

$\mathrm{F}=$ results obtained using the Fisher's exact test

$\mathrm{c}=$ result obtained through the chi-square test of independence

$\mathrm{n}=$ Number of cases

Table 8. Frequency of Adenovirus antigen according to some medial laboratory considerations.

\begin{tabular}{llll}
\hline Variables & Categories & Adenovirus positive: n(\%) & Adenovirus negative : n(\%) \\
\hline \multirow{3}{*}{ Stool colour } & Whitish & $1(50)$ & $1(50)$ \\
& Yellowish & $26(30.2)$ & $60(69.8)$ \\
& Greenish & $6(21.4)$ & $22(78.6)$ \\
& Brownish & $5(23.8)$ & $16(76.2)$ \\
& Slimy (Glair) & $5(20)$ & $20(80)$ \\
Stool consistency & Liquid & $26(33.8)$ & $51(66.2)$ \\
& Soft & $7(20)$ & $28(80)$ \\
Leucocytes & Present & $19(53.7)$ & $22(46.3)$ \\
& Absent & $37(22)$ & $131(78)$ \\
Yeast cells & Present & $9(20)$ & $35(80)$ \\
& Absent & $47(28)$ & $119(72)$ \\
\hline
\end{tabular}

*= results obtained using Kruskal Wallis test for group comparison of means;

$\mathrm{F}=$ results obtained using the Fisher's exact test;

$\mathrm{n}=$ Number of cases

\subsubsection{Relationship Between Various Variables and the Adenovirus Positivity of Patients After Multivariate Analysis}

We performed a logistic regression considering Adenovirus positivity as outcome variable. The included dependent variable were: age, sex, fever, and presence of leucocytes in stool, severity of dehydration, admission status, vomiting, abdominal pain, number of stools per day.

The variables that were significantly associated with adenoviral antigen were the presence of leucocytes in stool and the severity of dehydration (Table 9).

Children with leucocytes in stool were 3.2 times more likely to be infected than those who had no leucocytes in stool (OR 3.2; 95\% CI = 1.1 - 8.9). Moderately dehydrated children were 3.8 times more likely to have Adenovirus in stool than those that were mildly dehydrated (OR $3.8 ; 95 \%$ $\mathrm{CI}=1.2-13)$. Severely dehydrated children were 26 times more likely to Adenovirus in stool than those that were mildly dehydrated (OR $26 ; 95 \% \mathrm{CI}=4.1$ - 214). 
Table 9. Relationship between various clinical variables and Adenovirus positivity according to the logistic regression analysis.

\begin{tabular}{|c|c|c|c|c|}
\hline Categories & Estimate & SE & P-value & Adjusted OR (95 \%CI) \\
\hline Intercept & -1.69 & 0.875 & 0.04 & \\
\hline Fever (no) & Reference & & & \\
\hline Fever (yes) & 0.09 & 0.52 & 0.84 & \\
\hline Leucocytes(no) & Reference & & & \\
\hline Leucocytes(yes) & 1.16 & 0.51 & 0.02 & $3.2(1.17-8.9)$ \\
\hline Dehydration (mild) & Reference & & & \\
\hline Dehydration (moderate) & 1.3 & 0.5 & 0.03 & $3.8(1.2-13)$ \\
\hline Dehydration (severe) & 3.27 & 0.99 & 0.001 & $26.5(4.11-214)$ \\
\hline Age & 0.001 & 0.01 & 0.9 & \\
\hline Sex(female) & Reference & & & \\
\hline Sex (male) & -0.15 & 0.44 & 0.72 & \\
\hline Abdominal pain (Negative) & Reference & & & \\
\hline Abdominal pain (yes) & -1.25 & 0.82 & 0.12 & \\
\hline Number of stool per day & -0.11 & 0.15 & 0.4 & \\
\hline Vomiting (no) & Reference & & & \\
\hline Vomiting (yes) & -1.07 & 0.61 & 0.07 & \\
\hline Outpatient & Reference & & & \\
\hline In patient & 0.96 & 0.5 & 0.07 & \\
\hline
\end{tabular}

\subsection{Rotavirus Antigen}

\subsubsection{Group A Rotavirus Prevalence}

We found only 5 samples that were positive to group A Rotavirus which gave a prevalence of $2.31 \%$ as shown on Table 10.

\subsubsection{Frequency of Group A Rotavirus with Respect to Clinical Outcome}

Table 11 shows the distribution of RVA according to clinical data and the $P$ values obtained after bivariate analyses. We found that the prevalence of RVA was significantly higher in children who vomited more than five times $(P=0.03)$. Table 12 shows that RVA positive children had a more prolonged vomiting duration than RVA negative children. The mean numbers of vomiting, the mean numbers of stool episodes were significantly higher in RVA positive children than in RVA negative. We did not find any association with the management of dehydration, the admission status, the dehydration severity, temperature and vomiting duration.

Table 10. Positivity Rate of Group A Rotavirus.

\begin{tabular}{lllll}
\hline RVA antigen & Number positive & Frequency & $\mathbf{9 5 \%}$ CI \\
\hline Positive & 5 & $2.31 \%$ & $0.77 \%$ & $5.39 \%$ \\
Negative & 207 & $97.6 \%$ & $94.61 \%$ & $99.23 \%$ \\
\hline
\end{tabular}

Table 11. Clinical data and Group A Rotavirus status.

\begin{tabular}{|c|c|c|c|c|}
\hline Variable & Category & Rotavirus positive: $\mathrm{n}(\%)$ & Rotavirus negative : n(\%) & $P$-value \\
\hline \multirow{3}{*}{ Number of stool per day } & $1-3$ & $1(1.2)$ & $85(98.8)$ & \multirow{3}{*}{$0.1^{\mathrm{F}}$} \\
\hline & $4-5$ & $3(2.45)$ & $40(97.5)$ & \\
\hline & $\geq 6$ & 0 & $33(100)$ & \\
\hline \multirow{3}{*}{ Diarrhoea duration (days) } & $1-4$ & $3(75)$ & $119(65)$ & \multirow{3}{*}{$0.83^{\mathrm{F}}$} \\
\hline & 5 & 0 & $13(7.1)$ & \\
\hline & $\geq 6$ & $1(25)$ & $51(27.9)$ & \\
\hline \multirow{3}{*}{ Vomitting } & Yes & $4(5.7)$ & $66(94.3)$ & \multirow{3}{*}{$0.0578^{\mathrm{F}}$} \\
\hline & No & $1(0.8)$ & $123(99.2)$ & \\
\hline & 0 & $1(0.8)$ & $119(99.2)$ & \\
\hline \multirow{3}{*}{$\begin{array}{l}\text { Number of Vomiting } \\
\text { Episodes/day }\end{array}$} & 1 & 0 & $21(100)$ & \multirow{3}{*}{$0.03^{\mathrm{F}}$} \\
\hline & $2-4$ & $3(7.9)$ & $35(92.1)$ & \\
\hline & $\geq 5$ & $1(10)$ & $9(90)$ & \\
\hline \multirow{4}{*}{ Vomiting duration (days) } & 0 & $1(0.84)$ & $117(99.16)$ & \multirow{4}{*}{$0.1^{\mathrm{F}}$} \\
\hline & 1 & $1(7.1)$ & $13(92.9)$ & \\
\hline & 2 & 0 & $12(100)$ & \\
\hline & $\geq 3$ & $2(4.34)$ & $44(95.65)$ & \\
\hline \multirow{3}{*}{ Fever } & Yes & $4(4.4)$ & $86(93.6)$ & \multirow{3}{*}{$0.193^{\mathrm{F}}$} \\
\hline & No & $1(10)$ & $98(90)$ & \\
\hline & $<37.9$ & $1(1.25)$ & $79(98.75)$ & \\
\hline \multirow{3}{*}{ Temperature $\left({ }^{\circ} \mathrm{C}\right)$} & $38-38.9$ & $3(37.5)$ & $5(62.5)$ & \multirow[t]{3}{*}{$0.4^{\mathrm{F}}$} \\
\hline & $39-39.9$ & $1(5)$ & $19(95)$ & \\
\hline & $\geq 40$ & 0 & $8(100)$ & \\
\hline
\end{tabular}




\begin{tabular}{lllll}
\hline Variable & Category & Rotavirus positive: $\mathbf{n}(\%)$ & Rotavirus negative : n(\%) & P-value \\
\hline \multirow{3}{*}{ Dehydration } & Mild & $1(1.23)$ & $81(98.76)$ & \\
& Moderate & $2(2.5)$ & $78(97.5)$ & $0.33^{\mathrm{F}}$ \\
& Severe & $2(6)$ & $31(94)$ & \\
\multirow{2}{*}{ Management of Dehydration } & Plan A & 0 & $26(100)$ & $0.15^{\mathrm{F}}$ \\
& Plan B & $2(1.88)$ & $104(98.1)$ & \\
\multirow{2}{*}{ Admission status } & Plan C & $3(6.9)$ & $40(93)$ & $0.6^{\mathrm{F}}$ \\
\hline
\end{tabular}

$\mathrm{F}=$ results obtained using the Fisher's exact test

$\mathrm{n}=$ Number of cases

Table 12. RVA status according to number of vomiting, diarrhoea episodes, age and weight.

\begin{tabular}{|c|c|c|c|}
\hline Parameter & $\begin{array}{l}\text { RVA positive } \\
\text { mean } \pm s d(\mathrm{n})\end{array}$ & $\begin{array}{l}\text { RVA Negative } \\
(\text { mean } \pm s d)(n)\end{array}$ & $P$-value \\
\hline Number of vomiting episodes & $4.5 \pm 2.2(5)$ & $2.67 \pm 1.74(186)$ & $0.02 *$ \\
\hline Duration of vomiting (days) & $2.5 \pm 2.38(4)$ & $0.98 \pm 3.45(187)$ & $0.1^{*}$ \\
\hline Number of diarrhoea episodes & $4.5 \pm 1.5(154)$ & $3.7 \pm 0.5(4)$ & $0.005^{*}$ \\
\hline Duration of diarrhoea (days) & $4.75 \pm 2.2(4)$ & $5.25 \pm 3.2(185)$ & $0.38^{*}$ \\
\hline Weight $(\mathrm{Kg})$ & $13.75 \pm 2.25(6)$ & $9.79 \pm 0.04(156)$ & 0.33 \\
\hline Age (years) & $16.6 \pm 9.48(12)$ & $17.6 \pm 0.17(129)$ & $0.2^{*}$ \\
\hline
\end{tabular}

*= results obtained using Kruskas Wallis test for group comparison of means

$\mathrm{n}=$ Total number of cases in each group

\subsection{Distribution of Group A Rotavirus Circulating Genotypes}

\subsubsection{Distribution of VP7 Genotypes}

Figure 1 show that genotype G1 was most the most predominant VP7 genotype (60\%). The remaining (2) VP7 genotypes were non-typable.

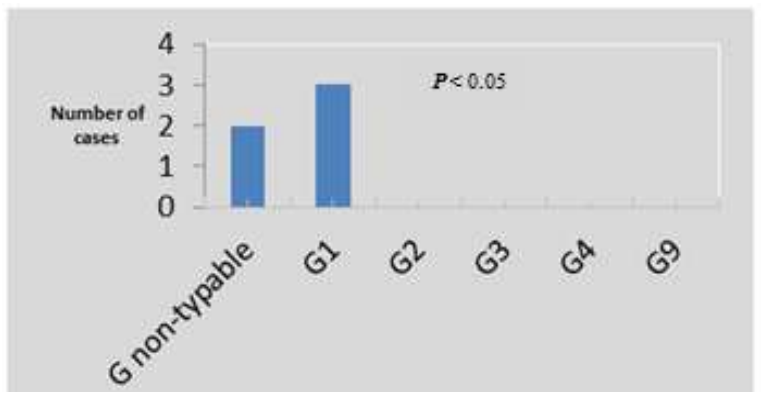

Figure 1. Distribution of VP7 (G) genotypes.

\subsubsection{Distribution of VP4 Genotypes}

Figure 2 below presents the distribution of VP4 genotypes. We can see from it that $\mathrm{P}[8]$ was more predominant, followed by P non typable VP4 genotype.

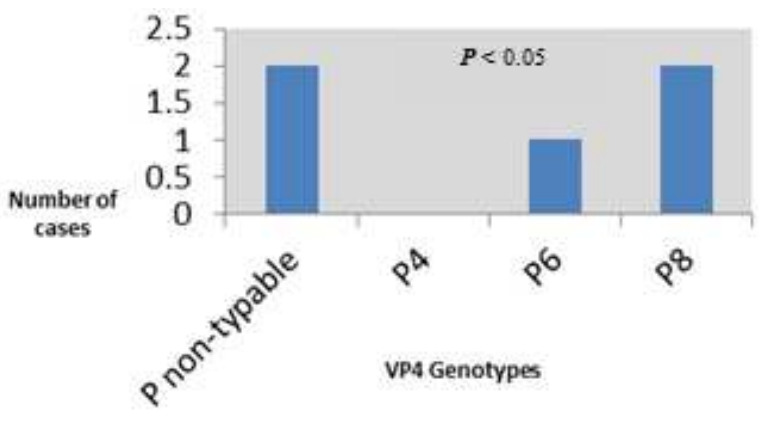

Figure 2. Distribution of VP4 (P) genotypes.

\subsubsection{Distribution of the G/P Combinations}

According to Figure 3, G1P[8] (40\%) was the most predominant genotype, followed by G1P[nt], G nt P[6] and Gnt P[nt], with each $20 \%$.

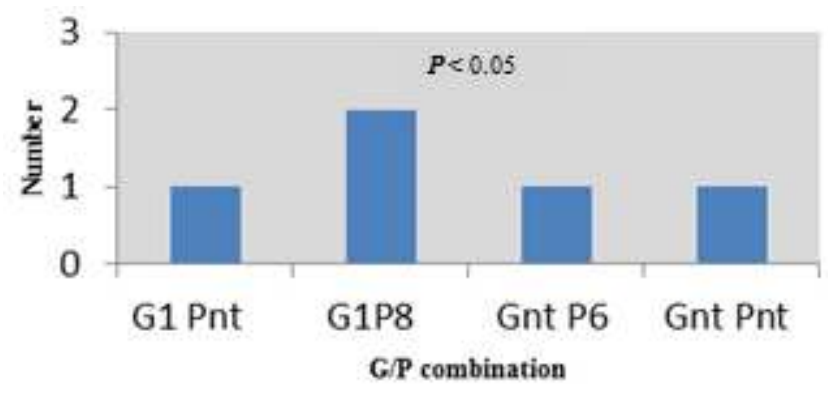

Figure 3. Distribution of the G/P combinations.

\subsection{Co-Infection by Group A Rotavirus and Adenovirus}

Co-infection with Rotaviruses was observed in 5.3\% (3/56) of patients. There were no significant relationships between co-infection and the existence of clinical symptoms observed in these children despite the differences in prevalence.

\subsection{Limits of the Study}

Scientific honesty allows us to admit that this study was not perfect, and thus, its limits are to be precised. Firstly, the inference of RVA related parameters obtained in this study doesn't really extend to the whole of Ngaoundere city, since we did not achieve our expected sample size of 345, calculated through the Lorenz formula. Secondly, the number of Rotaviruses we recorded was too low to perform statistical analyses with enough effect size to detect significant relationships. Finally, rapid testing is not the reference technique according to WHO and thus we could have obtained higher rate of false positives/negatives than the state 
of art techniques (RT-PCR). The low frequency of dual infection observed in this study didn't allow us to explore possible answers to the question whether a single virus is responsible for illness or whether the two viruses act in synergy.

\section{Discussion}

The $26 \%$ Adenovirus antigen's rate obtained in this study was closer to $22.3 \%$ reported in North-western Nigeria [20]. Another closer result to ours (23\%) was obtained by Mhalu and co-workers in Tanzania [23]. Nevertheless, the result we obtained is not consistent with the those obtained by Ndze and collaborators, who obtained a prevalence of $6.6 \%$ in Yaoundé [24]. It is however noteworthy to say that their sample size was very low (61 children) and that could explain the discrepancy in the results. More generally most studies report Adenovirus frequency infections comprised between $2-31 \%$ of diarrhoeas observed in the paediatric age group [25]. Divergence in results may be observed due the different climates or be attributed to study design or methodology.

In this study, we obtained a similar prevalence of Adenovirus in males $(27 \%)$ as in females $(26 \%)$. Most studies report a higher prevalence in males that in females. $[20,26]$. We found that age distribution according to gender was not statistically significant. In fact, all the age groups of our study had between 23 and 30\% prevalence. This result is divergent to that of Aminu and co-workers in Nigeria who found that children from 25 to 36 months were mostly positive for Adenovirus Antigen [20]. Ndze and co-workers noticed the highest prevalence in the $49-60$ month age group [24].

Children with leucocytes in stool were 3.2 times more likely to be infected than those who had no leucocytes in stool (OR 3.2; 95\% CI = 1.1 - 8.9). Children who had moderate dehydration were 3.8 times more likely to have Adenovirus in stool than those that were mildly dehydrated (OR $3.8 ; 95 \%$ CI = 1.2-13). Similarly, children who had severe dehydration were 26 times more likely to Adenovirus in stool than those that were mildly dehydrated (OR $26 ; 95 \%$ $\mathrm{CI}=4.1$ - 214). This results is certainly the consequence of the fact that the pathogenic Adenovirus 40/41 represents at least $50 \%$ of all adenoviruses usually found in stools [27] and they are probably highly prevalent in our study population.

$51.1 \%$ of children tested positive for Adenovirus antigen were hospitalised whereas, Aminu and co-workers in Nigeria reported that in group F adenovirus infected patient's treatment only $10 \%$ required hospitalization on visit [20]. In effect, in our study population, most cases of dehydration among children positive to Adenovirus antigen were severe forms requiring a Plan $\mathrm{C}$ management (Intravenous rehydration). There was a significant relationship between fever, vomiting and presence of Adenovirus in stool. Thus, these clinical features are similar to those previously described in Nigeria and in Iran [20][28]. In fact, vomiting, fever, dehydration are the consequences of the pathophysiological mechanism of enteric Adenovirus as described by Leppard and co-workers [29]. The observation of clinical signs and symptoms of this magnitude among our population still probably means that there is a high rate of group F and group A Adenovirus in our study population, and thus, further genotypic studies need to be undertaken in order to characterise them.

In Iran, Motamedifar and co-workers observed by logistic regression that, there was a significant relationship between Adenovirus infection, vomiting, dehydration, fever and fever + diarrhoea. They found no significant association between vomiting, abdominal pain, lethargy, polymorphonuclear cells (PNL) in stool, and nausea with rotavirus and Adenovirus infection [30]. We also did not find any association between abdominal pain, fatigue and Adenovirus infections. We also observed that the presence of PNL in stool was significantly associated with the presence of Adenovirus in stool. Pathogenic Adenoviruses are capable of initiating an inflammatory response, an immune response directed towards the viral antigens, thus, fever occurs, leucocytes are produced. [31]. During direct microscopy of diarrhoeic stools, the presence of PNL existence classically suggest inflammatory bacterial gastroenteritis [32]. Our results thus confirm that PNL can also be seen in the direct microscopy of viral gastroenteritis cases. In clinical examination, it is not possible to make a viral-bacterial distinction on basis of this data. Regarding treatment approach, it is important to know that, PNL existence in stool is not a gold standard for bacterial-viral agent differentiation; it may also be seen in viral cases.

Our results also suggest that there is no relation between the mode of feeding (breastfeeding, family meals, bottlefeeding) and the presence of Adenovirus antigen in stool. This result is in contrast with that of other authors. In Iran for instance, Modarres and co-workers observed that in infants up to nine months of age who were breast-fed there was an infection rate of $19.2 \%$, which is significantly $(P=0.004)$ lower than that in the bottle- fed growth (47.8\%) [28].

RVA positivity rate was $2.3 \%$ in our entire sample. Concluding that RVA gastroenteritis represents a low burden among the Ngaoundere children could be misleading. In fact, in Cameroon, published data show that Rotavirus positivity rate varies from $21.9 \%$ in western Cameroon [33] to $42.8 \%$ in far north [34] and 44\% in Yaoundé [35]. The literature also highlights the seasonality of the RVA infection in Northern Cameroon, and precises that the monthly prevalence of group A Rotavirus is at its highest level in November and December, followed by a decrease until it reaches its lowest level in rainy months of May, June, September and October [34, 36]. This finding of Ndze and co-workers applies to our study, as the sample collection was done from April to July 2014 (a season during which the prevalence or RVA is usually at its lowest level). Another argument to explain our result is that most RVA infections in the tropics usually occur in the dry months [37] which could be due to increased outdoor activities and exposure of children. Besides, Rotavirus inactivation is faster $\mathrm{n}$ waters with $\mathrm{pH}>8.0$ than in waters with $\mathrm{pH}<8.0$ [38-39]. 
This means that during rainy seasons, the increasing level of water further dilutes the said water, thus rendering the $\mathrm{pH}$ more basic, consequently reducing the load of RVA, which could probably be transmitted to humans. The results discrepancy observed in this study could be also due to the RVA detection method we used in this study (rapid method / immunochromatography), while most studies conducted in Cameroon used either Reverse Transcriptase-PCR or enzyme immunoassay (EIA) method [33-36].

Since the number of patients with Rotavirus-positive gastroenteritis was low in our entire study population, no statistical significance was determined for most variables (age, gender, Rotarix vaccination, clinical data, risks factors and laboratory parameters), except for the mean number of daily stool and the mean number of daily vomiting which were all significantly higher in rotavirus infected children. However, It is known that similarly to enteric adenoviruses, RVA induces severe dehydrating diarrhoea with fever and vomiting [40]. Furthermore, we found a significant association between the RVA and zone of Residence $(P<0.05)$; children living within the Ngaoundere 3 constituency were having the highest prevalence rate of RVA. In effect, Ngaoundere 1 and 2 subdivisions are urban and Ngaoundere 3 sub-division is a rural one, thus confirming the results of Ndze and co-workers who found that children in rural areas were more vulnerable to RVA than children living in urban areas [34].

Globally, five strains are most commonly detected: G1P[8], G2P[4], G3P[8], G4P[8], and G9P[8] [40]. In our study, the main circulating genotype we detected was G1P[8] genotype (40\%) followed by G1P[nt] (20\%), GntP[6] (20\%) and GntP[nt] (20\%). This result is in accordance with our initial hypothesis which stipulated that the distribution of RVA strains in Ngaoundere are different from those frequently observed in the world. This genotype is the locally and globally predominant and is the primary genotype from which the Rotarix vaccine was made [41]. Thus, there was no G2P[4] and G9P[6] strains which are not covered by Rotarix vaccine. Nonetheless it will be important to monitor the spatiotemporal dynamics of emerging strains, which might become predominant after rotavirus vaccines are used in massive immunization programs. Those strains that share no G- and P-type specificities with strains in RotaTeq or Rotarix may be challenging to existing rotavirus vaccines.

Of Rotavirus-positive specimens, two samples remained untypeable for $G$ type, two for $P$ type, and one for both $G$ type and P type. Possible explanations include too few virus particles with intact RNA in the stool specimens, the viruses not being recognized by the primer sets, and the viruses not belonging to genotypes included in the primer set.

\section{Conclusion}

Human rotaviruses are circulating in Ngaoundere, with the G1P[8] as the most common strain. We can thus affirm that the Rotarix vaccine can provide a protective immunity against the rotavirus strains circulating in Ngaoundere. Our study further highlights the $26 \%$ rate of Adenovirus antigen in diarrhoeic stools, as well as its relationships with clinical condition (fever, dehydration, presence of leucocytes stool, fever, vomiting), quarter of residence and socio-demographic parameters. The types of water consumed, the mode of nutrition, Parent/ guardian's occupation, ethnic group and vaccination status were not significantly related to Adenovirus infection. We also found that there were no significant relationships between co-infection and the prevalence of clinical symptoms observed in these children despite the differences in prevalence.

Regional epidemiological information on rotavirus and Adenovirus infections may be important to define strategies for intervention and for an improved use of the Rotavirus vaccine. This study highlights the need of continuous surveillance and monitoring of acute gastroenteritis caused by rotavirus to monitor the potential vaccine impact on population. Future studies should: Characterise the detected Adenoviruses and carry out phylogenetic studies in order to explore the probable links between the viruses or their origin. The phylogenetic study should also involve RVA strains detected. Another perspective would be to do an in-depth investigation of the determinants of the RVA infection in the Ngaoundere 3 Sub-division and to study the molecular epidemiology of enteric Adenovirus infection in the remaining regions of Cameroon.

\section{Acknowledgements}

The authors are thankful to the participants of this study in Ngaoundere who provided samples and shared their valuable time to fill their questionnaire. We also thank the personnel of all the study sites for their help during data and sample collection.

\section{References}

[1] UN. "United Nations millennium development goals", [cited 2014 October 23]; Available from: http://www.un.org/millenniumgoals/.

[2] WHO. "Diarrheal disease", Media Centre [cited 2014 December 2014]; Available from: http://www.who.int/mediacentre/factsheets/fs330/en/index.ht $\mathrm{ml}$.

[3] S. Levidiotou, C. Gartzonika, D. Papaventsis, C. Christaki, E. Priavali, N. Zotos, E. Kapsaliand G. Vrioni, "Viral agents of acute gastroenteritis in hospitalized children in Greece.", Clin. Microbiol. Infect., vol. 6(15), 2009, pp. 596-598.

[4] D. L. Pacini, A. M. Collierand F. M. Henderson, "Adenovirus infections and respiratory illnesses in children in group day care", J.Infect Dis. , vol. 156, 1987, pp. 920-926.

[5] D. Subekti, M. Lesmana, P. Tjaniadi, N. Safari, E. Frazier, C. Simanjuntak, S. Komalarini, J. Taslim, J. R. Campbelland B. A. Oyofo, "Incidence of Norwalk-like viruses, rotavirus and adenovirus infection in patients with acute gastroenteritis in Jakarta, Indonesia", FEMS Immunol Med Microbiol, vol. 33(1), 2002 pp. 27-33. 
[6] F. Stevenson and V. Mautner, "Aspects of the molecular biology of enteric adenoviruses",in Perspectives in Medical Virology Viral Gastroenteritised., U. Desselberger, Editor., Elsevier, 2003, pp. 389-406.

[7] WHO. "Estimated rotavirus deaths for children under 5 years of age: 2008, 453 000", [cited 2014 May 12]; Available from: http://www.who.int/entity/immunization/monitoring_surveilla nce/burden/estimates/rotavirus/ChildRota2008.xls.

[8] INS, "Rapport final du TBS(Tableau de Bord social) 3 sur la situation sociale des enfants et des femmes au Cameroun ",in., 2009, pp. 47

[9] G. M. Ruiz-Palacios, I. Perez-Schael, F. R. Velazquez, H. Abate, T. Breuer, S. C. Clemens, B. Cheuvart, F. Espinoza, P. Gillard, B. L. Innis, Y. Cervantes, A. C. Linhares, P. Lopez, M. Macias-Parra, E. Ortega-Barria, V. Richardson, D. M RiveraMedina, L. Rivera, B. Salinas, N. Pavia-Ruz, J. Salmeron, R. Ruttimann, J. Valdesuso, C. Tinoco, P. Rubio, E. Nunez, M. L. Guerrero, J. P. Yarzabal, S. Damaso, N. Tornieporth, X. SaezLlorens, R. F. Vergara, T. Vesikari, A. Bouckenooghe, R. Clemens, B. De-Vosand M. O'Ryan., "Safety and efficacy of an attenuated vaccine against severe rotavirus gastroenteritis. ", N Engl J Med, vol. 354, 2006, pp. 11-22.

[10] Wikipedia. "Géographie du Cameroun", Géographie de l'Afrique 2 march 2015 [cited 20155 April ]; Available from: http://fr.wikipedia.org/wiki/G\%C3\%A9ographie_du_Camerou n\#Le_domaine_tropical.

[11] BUCREP,"Rapport de présentation des résultats définitifs du 3 è RGPH", Editor: Yaounde, 2005.

[12] Climatemps. "Ngaoundere Climate \& Temperature", [cited 2015 March 5]; Available from: http://www.ngaoundere.climatemps.com/map.php.

[13] WHO,"Generic protocols for hospital-based surveillance to estimate the burden of rotavirus gastroenteritis in children and a community-based survey on utilization of health care services for gastroenteritis in children (Field test version)", Editor WHO: Geneva, 2002.

[14] Biocare,"Instructions for use of the Rota/Adeno Combo Dipstick", Editor Biocare 2010, pp. 1-2.

[15] J. R. Gentsch, R. I. Glass, P. Woods, V. Gouvea, M. Gorziglia, J. Flores, B. K. Dasand M. K. Bhan, "Identification of group A rotavirus gene 4 types by polymerase chain reaction", J Clin Microbiol vol. 30, 1992, pp. 1365-1373.

[16] V. Gouvea, R. I. Glass, P. Woods, K. Taniguchi, H. F. Clark, B. Forresterand Z. Y. Fang, "Polymerase chain reaction amplification and typing of rotavirus nucleic acid from stool specimens", J Clin Microbiol vol. 28, 1990, pp. 276-282.

[17] WHO,"Manual of rotavirus detection and characterization methods (WHO/IVB/08.17)", Editor Expanded Programme on Immunization, Department of Immunization, Vaccines and Biologicals: Geneva, 2009, pp. 146.

[18] J.M. Last, "A Dictionary of Epidemiology". Oxford: Oxford University Press, 2001, pp.

[19] A. Krämer, M. Akmatovand M. Kretzschmar, "Modern Infectious Disease Epidemiology, Statistics for Biology and Health",in., Springer Science+Business Media, 2010, pp. 8587.

[20] M. Aminu, A. A. Ahmad, J. U. Umoh, M. C. de-Beer, M. D.
Esonaand A. D. Steele, "Adenovirus infection in children with diarrhea disease in Northwestern Nigeria", Ann Afr Med, vol. 6(4), 2007, pp. 168-73.

[21] WHO. "Portail d'information - Médicaments essentiels et produits de santé; Une ressource de l'Organisation mondiale de la Santé", 10 February 2015 [cited 2015 April 5]; Available from:

http://apps.who.int/medicinedocs/fr/d/Jwhozip29f/7.3.html.

[22] L. Kristen, "Vesikari Clinical Severity Scoring System Manual". PATH 2011, pp.

[23] F. S. Mhalu, H. Myrmel, A. Msengiand G. Haukenes, "Prevalence of infection with Rotavirus and enteric Adenoviruses among children in Tanzania", NIPH Ann., vol. 11, 1988, pp. 3-7

[24] V. N. Ndze, D. Adiogo, C. N. Fokunang, K. H. Gonsu, E. A. Tembe-Fokunangand O. M. T Abena, "Enteric Prevalence of Rotavirus and Adenovirus in Under Five Children Predisposed to Acute Diarrhea in Yaounde Cameroon", Health Sci. Dis, vol. 11(3), 2010.

[25] I. Wilhelmi, E. Romanand A. Samchez-Fauquiera, "Viruses causing gastroenteritis.", Clin. Microbiol. Infect, vol. 9, 2003, pp. $247-262$.

[26] R. Hamkar, "Prevalence of Rotavirus,Adenovirus, and Astrovirus Infections among Patients with Acute Gastroenteritis in, Northern Iran. ", Iranian J Publ Health, vol. 39(2), 2010, pp. 45-51

[27] Z. A. R. Samarbaf, R. Pirmoradi, A. Shamsizadehand M. Makvandi, "Prevalence of adenoviruses 40 and 41 in children less than five years suffering from acute gastroenteritis hospitalized in Ahvaz Abuzar Hospital", Jundishapur Journal of Microbiology, vol. 2, 2010, pp. 48-52.

[28] S. Modarres, F. Jam-Afzonand S. Modarres, "Enteric Adenovirus infection in infants and young children with acute Gastroenteritis in Tehran", Acta Medica Iranica, vol. 44(5), 2006 pp. 349-353.

[29] K. N. Leppard,"Adenoviruses: Molecular Biology", Editor Academic Press: University of Warwick, Coventry, UK, 2008, pp. 419-425.

[30] M. Motamedifar, A. Elhamand T. S. Pedram, "Frequency of Rotavirus and Adenovirus Gastroenteritis Among Children in Shiraz, Iran", Iranian Red Crescent Medical Journal, vol. 15(8), 2013, pp. 729-733.

[31] M. R. G. O'Gorman and A. D. Donnenberg, "Handbook of human immunology". ed. R.G. Maurice and D.A. Donnenberg. CRC Press, 2008, pp 429.

[32] R.P. Silletti, G. Leeand E. Ailey, "Role of stool screening tests in diagnosis of inflammatory bacterial enteritis and in selection of specimens likely to yield invasive enteric pathogens", Journal of Clinical Microbiology, vol. 34(5), 1996, pp. 1161-1165.

[33] M. D. Esona, G. E. Armahand A. D. Steele, "Molecular epidemiology of rotavirus infection in Western Cameroon", J Trop Pediatr, (49), 2003, pp. 160-163.

[34] V. N. Ndze, E. A. Achidi, H. K. Gonsu, E. E. Lyonga, M. D. Esona, B. Krisztianand M. T. Obama, "Epidemiology of rotavirus diarrhea in children under 5 years in Northern Cameroon", Pan African Medical Journal, , 2012, pp. 73. 
[35] A. Boula, D. Waku-Kouomou, M. N. Kinkela, M.D. Esona, G. Kemajou, D. Mekontsoc, S. Mapaseka, V. N. Ndze, I. Emahe, S. Ela, B. A. Dahlf, M. Kobela, F. Kathleen, Cavallaro, G. A. E. Mballa, J. R. Genstch, M. D. Bowenand P. K. Ndombo, "Molecular surveillance of rotavirus strains circulating in Yaoundé, Cameroon, September 2007-December 2012", Infect Genet Evol, 2014

[36] F. A. Mbuh, A. G. Enyimah, S. A. Omilabu, A. A. Ahmadand J U. Umoh, "Molecular epidemiology of group A human rotaviruses in North West region, cameroon", Pan African Medical Journal, vol. 12(108), 2012, pp. 1-8.

[37] K. Levy, E.H. Alanand N.S.J. Eisenberg, "Seasonality of rotavirus disease in the tropics: a systematic review and metaanalysis", Int J Epidemiol, vol. 38(6), 2009, pp. 1487-1496.
[38] R.L. Ward and C.S. Ashley, "Identification of the virucidal agent in wastewater sludge.", Appl Environ Microbiol, vol. 33, 1977, pp. 860-864

[39] O. C. Pancorbo, " Infectivity and antigenicity reduction rates of human rotavirus strain WA in fresh waters", Appl Environ Microbiol, vol. 53(8), 1987, pp. 1803-1811.

[40] CDC,"The Pink Book: Course Textbook ", Editor 2012, pp. 263-274.

[41] WHO, "Rotavirus vaccines: an update", World Health Organization, Weekly Epidemiological Record, (84), 2009, pp. 533-540. 